\title{
Xian Huang, Social Protection under Authoritarianism
}

\author{
(New York: Oxford University Press, 2020), 280p, \$74.00 hardback
}

\section{Kerry Ratigan ${ }^{1}$}

Accepted: 10 February 2021 / Published online: 2 March 2021

(c) Journal of Chinese Political Science/Association of Chinese Political Studies 2021

Huang's book addresses an enduring puzzle in political science: why and how do authoritarian regimes expand welfare provision? Huang's answer is that China's central leaders use social welfare expansion to bolster regime legitimacy using a "stratified expansion strategy." Through her incisive analysis of China's Social Health Insurance (SHI) in the 2000s, Huang convincingly argues that the Chinese party-state has simultaneously expanded health insurance coverage to the masses and preserved the stratification of Chinese society by offering premium benefits to elites.

Autocratic leaders must determine how to distribute welfare benefits. If they provide universal benefits to all, then elite groups may be displeased. But if they tolerate high inequality, only providing benefits to elites, then the masses may revolt. Huang offers a theoretical framework to understand how autocrats navigate this dilemma. By providing expanded—but stratified-welfare, autocrats balance the demands of elites and masses to appease both groups.

Preparing the reader for her analysis of SHI, Huang demonstrates that the Center allocates more fiscal transfers to provinces with larger elite groups (civil servants, urban hukou holders, SOE employees), despite CCP rhetoric suggesting that fiscal transfers target the poorest provinces. In fact, most transfers are allocated to elites, such as government employees, who comprise a small proportion of the population. These findings suggest that fiscal transfers are politically motivated and used to support political stability.

Huang explains that the 2003 Social Insurance Law expanded social insurance but also institutionalized stratification in the health insurance system, rather than taking a universal approach. In early 2000s China, four insurance programs were dominant and eligibility for each of these programs was dependent on one's socioeconomic status-such as urban or rural hukou, civil servant, or employment in the public or private sector-thereby preserving a high level of stratification. Civil servants were eligible for the generous Government Insurance Scheme,

Kerry Ratigan

kratigan@amherst.edu

1 Amherst College, Amherst, MA, USA 
while a farmer was only eligible for the New Rural Cooperative Medical Scheme, providing meagre benefits.

Huang also elucidates local variation in SHI provision and identifies four distinct approaches to how the provinces implement SHI. To this end, Huang disaggregates SHI benefits along three dimensions: generosity, coverage, and stratification. Using these metrics, Huang employs cluster analysis to identify regional patterns in SHI provision. She finds that differences in SHI provision are associated with a province's economic and demographic profile. While some wealthier provinces increased both coverage and generosity, others focused benefits on elite groups, such as party officials, civil servants, SOE employees, or local urban hukou holders. Some poorer provinces provided only minimal levels of generosity and coverage. Meanwhile, other cash-strapped provinces opted for more expansive coverage, but shallow benefits, due to high levels of social risk from outgoing migration.

Huang highlights complex tensions between levels of government, as the Center tasks local government with policy implementation. For example, she notes the surprising experience of Dongguan, where the city exceeded central government policy by offering a more universal model of health insurance. Rather than being lauded by the Center for their accomplishments, city officials reported being chastised and pressured to offer select additional benefits to civil servants to retain privileges for this elite group. This case and other qualitative evidence presented in the book suggest that stratification is a priority for the central government, not an accident of implementation.

Huang's book provides an invaluable analysis of SHI during the early 2000s, but future research could examine whether China's welfare system is changing under Xi Jinping. As Huang mentions, as of 2017, Xi's government appears to be maintaining a stratified healthcare system. But, under Xi, the CCP has taken measures to recentralize power, reducing the role of local government in shaping policy implementation. What will the implications of recentralization be for the local variation in SHI that Huang identifies? Moreover, will the COVID-19 pandemic impact either the stratification or the decentralization of the healthcare system? Future research might examine these questions.

Huang finds that SHI expansion increased coverage of health insurance but maintained stratification based on enduring cleavages in Chinese society: rural and urban residents, labor market insiders and outsiders, state and private sector. Because SHI expansion further entrenched societal stratification, these health insurance programs did not resolve concerns about healthcare access and cost. With her penetrating insights and rigorous empirical analysis of quantitative and qualitative data, Huang's book offers a comprehensive examination of China's health insurance system in the 2000s. This book is a fundamental resource for scholars and students who are interested in social policy and regime stability in China. 
Kerry Ratigan is an Assistant Professor of Political Science at Amherst College. From 2018 to 2020, she was also the Pre-tenure Fellow for China- Latin America-US Affairs at the Foreign Policy Institute at the Johns Hopkins School of Advanced International Studies (SAIS). Her research focuses on Chinese politics, social policy, decentralization, and state-society relations, including work on health policy adoption and implementation in rural China. Her forthcoming book, Let Some Get Healthy First, examines how local politics shaped social policy provision in China. She has published research in World Development, The China Quarterly, International Political Science Review, Journal of Chinese Governance, Journal of Comparative Policy Analysis, and Journal of Asian Public Policy. She received her Ph.D. in Political Science from the University of Wisconsin-Madison. 